\title{
Development and Validation of Implicit Measures for Organizational Climate
}

\author{
Kailey A. Meyer \\ University of North Carolina - Charlotte \\ Donald L. Fischer \\ Missouri State University
}

\begin{abstract}
Organizational climate is the shared perceptions and valuations people hold about their experiences in the workplace. Organizational climate research has relied upon self-report measures, which can be influenced by impression management and inaccurate self-knowledge artifacts. This research used IAT procedures to develop measures of selected aspects of organizational climate and examined the relationships of the implicit measures with theoretically related explicit measures according to a multitrait-multimethod design. Confirmatory factor analyses of alternative latent trait models provided evidence of convergent and discriminant validity. Future research might focus upon developing measures with better psychometric properties and exploring the potential for incremental predictive validity.
\end{abstract}

Keywords: organizational climate, Implicit Association Test, multitrait-multimethod, construct validity

\section{INTRODUCTION}

Organizational climate represents one way to study how people conceptualize and organize experiences that occur within the workplace, and it has become an increasingly popular research topic over the past half century (Schneider et al., 2017). While there is no consensus upon how organizational climate should be defined in the literature, Schneider et al. (2017) offer this comprehensive description:

"[organizational climate is] a summary perception derived from a body of inter-connected experiences with organizational policies, practices and procedures (e.g., from leadership and HR practices, and so forth) and observations of what is rewarded, supported and expected in the organization with these summary perceptions becoming meaningful and shared based on the natural interactions of people with each other" (p. 468).

Research has established that organizational climate is a multidimensional construct. For example, James and James (1989) describe a hierarchical model that identifies four organizational climate factors at the penultimate level under a general evaluative dimension. The four higher-order factors include leader support and facilitation, role stress and lack of harmony, job challenge and autonomy, and workgroup cooperation. This study focusses on two of these factors - leadership and role stress.

Many scholars have stressed that leadership is an important component of climate (Gaviria-Rivera \& Lopez-Zapata, 2019; Kozlowski \& Doherty, 1989; Likert, 1967; Litwin \& Stringer, 1968). While James 
and James (1989) decompose leadership into five distinct facets, the current research will focus on leadership as a whole. Leader support is defined by Jones and James (1997) as "the extent to which the leader is aware of and responsive to the needs of his subordinates. [It involves] behavior which enhances someone else's feelings of personal worth and importance" (p. 31). Research has also established that there are destructive, counterproductive forms of leadership that involve abuse and disengagement. Kelloway and colleagues (2005) state that abusive leadership occurs when "individuals in a formal leadership role engage in aggressive or punitive behavior toward their employees" (p. 91). Examples of abusive supervision include rude comments, name calling, or even job loss (Kelloway et al., 2015; Mawritz et al. 2012). Mawritz et al. (2012) examined the influence of abusive supervision on subordinates and other employees. Results suggested that the abusive supervisor behavior not only impacted direct subordinates, but also employees at lower levels, emphasizing the negative impact of abusive behaviors. Passive leadership is also dysfunctional (Kelloway et al. 2005; Puni et al. 2016; Skogstad et al. 2007). Puni et al. (2016) examined the relationships between leadership styles and counterproductive work behavior and found that laissezfaire leadership resulted in an increase of counterproductive work behavior. Skogstad and colleagues (2007) found that laissez-faire leadership is positively related to role conflict and role ambiguity.

Role stress is another component of the organizational climate model developed by James and James (1989). Just as leader support can be subdivided into component facets, so can role stress. Role stress consists of role ambiguity, role conflict, role overload, submit conflict, organizational identification, and management concern and awareness (James \& James, 1989). The current research will only focus on role ambiguity and role conflict. Jones and James (1977) defined role conflict as "the presence of pressure for conflicting or mutually exclusive behaviors" (p. 31) and role ambiguity as "the extent to which a task is unclear in its demands, criteria, or relationships with other tasks" (p. 31). Both of these definitions are consistent with those offered by others (Rizzo et al., 1970; Schuler et al., 1977).

Organizational climate is important for both organizations and individuals (Ostroff et al., 2012; Svyantek \& Bott, 2004). Research has demonstrated that organizational climate can have an influence on an employee's emotional wellbeing (Thakre \& Shroff, 2016), intent to stay with an organization (Shanker, 2014), organizational citizenship behavior (Organ, 1988), organizational safety climate (Neal et al. 2000), organizational commitment (Shanker, 2015), innovative behavior (Hsu \& Chen, 2017), and knowledgesharing behavior (Kim \& Park, 2020). Researchers have explored how organizational climate can moderate important relationships. In a pioneering study, Litwin and Stringer (1968) found that organizational climate moderates the relationship between motivation and satisfaction/performance involving three fundamental needs: achievement, affiliation, and power. More recently, Y1ldız and Özcan (2014) found that organizational climate moderates the relationship between transformational leadership behavior and subordinate creativity. Vong et al. (2018) found that organizational climate moderates the relationship between job stress and intent to stay, such that employees were more likely to stay in organizations with a supportive climate. Further, Schneider (1974) found that job-related individual differences were better predictors of job performance and satisfaction in organizations that had a climate with supportive leadership, coworker unity/cooperation, autonomy, and an emphasis on development. Consequently, interventions that target basic human resource functions (e.g., selection and training programs) had greater impact when implemented in climates that reflect these characteristics. This research makes clear the importance of considering shared perceptions of experiences in organizations.

\section{Measurement of Organizational Climate}

Much of the research on organizational climate has used "structured perceptions surveys" (Hellriegel \& Slocum, 1974; Svyantek \& Bott, 2004). These surveys typically involve individuals describing their work experiences by endorsing/denying statements or by rating statements on a Likert type scale (Furnham \& Goodstein, 1997; Insel \& Moos, 1972; Litwin \& Stringer, 1968; Thumin \& Thumin, 2011). While these measures have been found to be useful, they are susceptible to intentional distortion by individuals who are not motivated to respond in a truthful manner. Learly and Kowalski (1990) define impression management as "the process by which individuals attempt to control the impressions others form of them" (p. 34). For instance, when asked about supervision and leadership, an employee may not respond truthfully if their 
experiences are negative and they fear retaliation for saying so. One way to reduce the contaminating effects of impression management may be to use implicit measures to assess the target constructs.

\section{Implicit Association Test}

Implicit cognition is defined by Greenwald and Banaji (1995) as cognitions, feelings and evaluations that are not necessarily available to conscious awareness, conscious control, conscious intention, or selfreflection. The Implicit Association Test (IAT) was developed by Greenwald et al. (1998) to measure social cognitive constructs (attitudes, stereotypes, self-concept). Since the procedure's early use in measuring social attitudes, IATs have been developed to measure psychological attributes like self-esteem (Greenwald \& Farnham, 2000), integrity and character (Fischer \& Bates, 2008), Big Five personality traits (Steffens \& Konig, 2006), emotional intelligence (Oberdiear et al. 2016), and job satisfaction (Boyd, 2018).

The IAT is a reaction time-based measure computed from performance speeds on classification tasks, a procedure which is resistant to impression management and introspective self-knowledge artifacts, unlike explicit (self-report) measures. Participants sort stimuli according to target category-attribute pairs by pressing letters on the keyboard of a computer when stimuli from the various categories are presented one at a time on the screen. The faster and more accurately the performance on the sorting task, the stronger the association between the target and attribute. The slower and less accurate the performance, the weaker the association between the target and attribute (Lane et al., 2007).

Perhaps one of the more interesting findings of studies that employ implicit measures is that associations with explicit measures can vary (Greenwald et al., 2002). Much discussion has surrounded the association and disassociation between implicit and explicit measures of common constructs (Lane et al., 2007). MODE theory (Fazio \& Olsen, 2003) states that the more sensitive the domain, the greater the likelihood that motivational factors will be evoked and exert some influence on overt responses in explicit measures. MODE theory (an acronym for motivation and opportunity as determinants) predicts that if either the motivation or opportunity to deliberate is relatively low during the time of explicit response, explicit and implicit measures are expected to correlate. However, when both motivation and opportunity are relatively high, they are less likely to correlate. This would generally be the case with explicit measures of organizational climate when they are being administered in the workplace. In this case, implicit measures should have incremental validity for criterion behavior related to climate.

\section{Purpose}

The purpose of this study was to develop implicit measures for two important aspects of organizational climate: shared experiences related to leadership and role stress. This study seeks to examine the relationship between implicit and explicit measures of these attributes in accord with a multitraitmultimethod design (MTMM; Campbell \& Fiske, 1959). It is hypothesized that IAT measures of the selected organizational climate attributes (leadership and role stress) will be related to corresponding explicit measures of these attributes (evidence of convergent validity). It is also hypothesized that the measures of different climate attributes will be less related (evidence of discriminant validity). Finally, it is hypothesized that method factors will account for additional variance, so that the best fitting model for the MTMM data will include four factors - two climate factors (leadership and role stress) and two method factors (explicit and implicit). These hypotheses were evaluated using confirmatory factor analyses (CFA) of nested models, according to procedures described by Widaman (1985).

\section{METHOD}

\section{Sample}

A sample containing 153 subjects were recruited from a public university's introductory psychology classes. An a priori power analysis indicated that the sample size was near to that necessary for adequate power $(.80)$, given a null hypothesis of close fit $\left(\mathrm{H}_{0}: \mathrm{RMSEA}=.05\right)$ and an alternative hypothesis of poor fit $\left(\mathrm{H}_{\mathrm{A}}: \mathrm{RMSEA}=.10\right.$; MacCallum et al., 1996). 


\section{Explicit Measures}

Five explicit scales were employed in this study. The Index of Supervisor Support was used to measure perceptions of leadership (Ko et al., 2015). This scale is composed of nine items that are rated on a fourpoint Likert scale (strongly disagree-strongly agree). The Role Conflict and Role Ambiguity scales (Schuler et al., 1977) were used to measure the role stress experienced at work. The Role Conflict scale is composed of eight items and the Role Ambiguity scale is composed of six items, all of which are rated on a five-point Likert scale (strongly disagree - strongly agree). In addition, two subscales (Supervisor Support and Role Clarity) from the Work Environment Scales (Insel \& Moos, 1972) were used to evaluate the two target aspects of climate. Each of these measures is composed of nine items that respondents either endorse or deny according to whether they think the item describes their experience in the workplace.

\section{Implicit Measures}

This study used procedures described by Greenwald et al. (1998) to develop implicit measures of the selected climate constructs. In introducing the IAT, Greenwald et al. (1998) describe an IAT designed to assess one's attitudes toward flowers versus insects. The procedure involves two target categories (flowers and insects), and two attribute categories (pleasant and unpleasant). There are seven blocks of trials where, in the first block of trials, participants practice sorting stimuli from the target categories by pressing alternative letters on the keyboard (the "I" and "E" keys) as examples of flowers (e.g., rose, lily) and insects (e.g., moth, ant) are presented on the screen. In the second block of trials, participants practice classifying examples from the attribute categories as pleasant words (happy, wonderful) and unpleasant words (poison, awful) are presented. The third and fourth blocks pair a target category with an attribute category (e.g., flowers + pleasant and insects + unpleasant) and participants classify stimuli as they are presented on the screen. In the fifth block the assignment the keys for the attribute categories are switched and participants practice sorting only attribute stimuli, like they did in the second block. In the sixth and seventh blocks participants sort stimuli according to the reversed pairing of the target and attribute categories (i.e., flowers + unpleasant and insects + pleasant). The IAT score is a function of the difference in the mean reaction times for the alternative pairings - i.e., blocks three and four versus blocks six and seven.

Another type of implicit measure is the single target IAT (Karpinski \& Steinman, 2006). Unlike the original seven block IAT, the single target IAT consists of five blocks where, in the first block, participants sort stimuli from the two attribute categories (i.e., pleasant or unpleasant words). The second and third blocks pair target stimuli (e.g., animals like sheep, dog, etc.) with an attribute category (e.g., animal + pleasant). In the fourth and fifth blocks the target is paired with the alternate attribute category (e.g., animal + unpleasant). As with the seven-block procedure, the IAT score is a function of the difference in the mean reaction times for the blocks with alternative pairings - i.e., blocks two and three versus blocks four and five. As with the seven block procedure, larger IAT scores represent a stronger association between the categories in the first pairing, relative to the second pairing. Table 1 displays the structure of single target IATs.

\section{TABLE 1}

\section{SCHEMATIC OVERVIEW OF THE SINGLE TARGET IMPLICIT ASSOCIATION TEST}

\begin{tabular}{lll}
\hline Block & Left Key (“e”) & Right Key (“i”) \\
\hline $1^{*}$ & Good & Bad \\
$2^{*}$ & Good + Animal & Bad \\
$3^{* *}$ & Good + Animal & Bad \\
$4^{*}$ & Good & Bad + Animal \\
$5^{* *}$ & Good & Bad + Animal \\
\hline
\end{tabular}

*Practice Blocks; ** Test Blocks

The single target IAT procedure was used to develop four IATs designed to assess two aspects of organizational climate. More specifically, two IATs were developed to assess experiences with leadership 
and two IATs were developed to assess role experiences. For the role stress factor, one IAT involved conflict versus harmony attribute categories and one IAT involved ambiguity versus clarity attribute categories. Tables 2 and 3 display the category labels and word stimuli for these IATs. For the leadership factor, one IAT involved supportive versus disengaged attribute categories and one IAT involved supportive versus hostile attribute categories. Tables 4 and 5 display the category labels and word stimuli for these IATs. The guidelines provided by Lane et al. (2007) and Greenwald et al. (2003) were followed in developing the IATs. A series of pilot tests $(N=35, N=33, N=26)$ evaluated the psychometric properties of alternative category labels and word stimuli (e.g., mean classification error rates, IAT score variances, and internal consistency coefficients). The final set of category labels and stimuli were based upon the results of the pilot tests.

TABLE 2

CATEGORY LABELS AND WORD STIMULI FOR SINGLE TARGET ROLE CONFLICT IAT

\begin{tabular}{lll}
\hline Attribute-A: & Attribute-B: & Target: \\
Conflict & Harmony & Employment \\
\hline Stress & Balance & Work \\
Dispute & Unity & Task \\
Friction & Agree & Job \\
Hostility & Peace & Office \\
\hline
\end{tabular}

TABLE 3

CATEGORY LABELS AND WORD STIMULI FOR SINGLE TARGET ROLE AMBIGUITY IAT

\begin{tabular}{lll}
\hline Attribute-A: & Attribute-B: & Target: \\
Ambiguous & Clear & Employment \\
\hline Vague & Known & Work \\
Confuse & Certain & Task \\
Uncertain & Explicit & Job \\
Questionable & Definite & Office \\
\hline
\end{tabular}

TABLE 4

CATEGORY LABELS AND WORD STIMULI FOR SINGLE TARGET SUPERVISOR DISENGAGED IAT

\begin{tabular}{lll}
\hline Attribute-A: & Attribute-B: & Target: \\
Supportive & Disengaged & Supervisor \\
\hline Support & Ignore & Supervisor \\
Helpful & Indifferent & Boss \\
Respect & Uncaring & Manager \\
Assistance & Disregard & Administrator \\
\hline
\end{tabular}


TABLE 5

CATEGORY LABELS AND WORD STIMULI FOR SINGLE TARGET SUPERVISOR HOSTILITY IAT

\begin{tabular}{lll}
\hline Attribute-A: & Attribute-B: & Target: \\
Supportive & Mean & Supervisor \\
\hline Support & Attack & Supervisor \\
Helpful & Rude & Boss \\
Respect & Hostile & Manager \\
Assistance & Mean & Administrator \\
\hline
\end{tabular}

\section{Procedure}

Participants reported to a computer lab where all measures were administered under the supervision of research assistants. As part of the informed consent procedure, participants were told that they would be asked to describe aspects of their workplace experiences and that they should be thinking about the last few months of their current or most recent employment when responding. The order in which the scales were administered was constant across subjects and the implicit measures were interspersed with the explicit scales to reduce the mental fatigue that repeated IAT administrations can have. The order for all participants was as follows: demographic questions, two IATs, the explicit scales, followed by two IATs. ${ }^{1}$

\section{RESULTS}

Of the 153 participants, the majority were female (58\%) and non-Hispanic white (87\%). The mean age was 19.38 with three and a half years of work experience. Table 6 and Table 7 provide descriptive statistics and correlations for the study variables. ${ }^{2}$ Byrne (2010) reports that it is common to initially find inadmissible solutions when using CFA procedures with latent trait models and data from MTMM designs (Marsh, 1989). This can often be managed by imposing constraints on parameter estimates that are problematic (e.g., setting variance estimates that are inadmissible/negative to an appropriate fixed value). When efforts to achieve an admissible solution for the least restrictive model (Model 1) using this method proved unsuccessful, the explicit measures were parceled (Matsunaga, 2008), thereby significantly increasing the degrees of freedom for the model. Two indicator variables were created for each explicit measure by deriving scores based on the measures' even-numbered and odd-numbered items. This procedure produced admissible solutions for all models without imposing other constraints. The parceled measures are indicated by an "A" or "B" suffix to the original scale label in Table 7.

It is notable that most of the correlations between the implicit and explicit measures in Table 7 are small and non-significant - only two out of the 40 correlations in the heterotrait-heteromethod rectangle of the MTMM matrix are significant. It should also be noted that the reliabilities of the IAT measures are poor and do not meet the standard Nunnally (1978) recommends. This was a surprising result given the pilot test data that was analyzed. 
TABLE 6

DESCRIPTIVE STATISTICS FOR STUDY VARIABLES

\begin{tabular}{lcccccc}
\hline Variables & $\mathrm{N}$ & Min & Max & Mean & SD & Alpha \\
\hline Demographics & & & & & & \\
$\quad$ Age & 153 & 17 & 69 & 19.38 & 4.34 & NA \\
$\quad$ Years of Work & 153 & 1 & 48 & 3.49 & 3.95 & NA \\
Implicit Measures & & & & & & \\
$\quad$ Ambiguity & 153 & -.86 & .58 & -.21 & .27 & .22 \\
$\quad$ Conflict & 153 & -.91 & .75 & -.02 & .32 & .56 \\
$\quad$ Disengaged & 153 & -.69 & 1.00 & .29 & .29 & .47 \\
$\quad$ Hostile & 153 & -.71 & .94 & .23 & .30 & .52 \\
Explicit Measures & & & & & & \\
$\quad$ Role Ambiguity & 153 & 12 & 30 & 23.13 & 3.57 & .77 \\
$\quad$ Role Conflict & 153 & 8 & 39 & 32.69 & 5.76 & .79 \\
$\quad$ Supervisor Support & 153 & 9 & 36 & 26.95 & 5.38 & .90 \\
$\quad$ WES Clarity & 153 & 0 & 9 & 5.49 & 2.12 & .66 \\
$\quad$ WES Supervisor Support & 153 & 0 & 9 & 4.56 & 2.02 & .57 \\
\hline
\end{tabular}

Following Widaman's (1985) guidelines, fit statistics for nested CFA models were compared to obtain evidence of convergent and discriminant validity. The least restrictive model contains two freely correlated method factors and two freely correlated climate trait factors (see Figure 1). Model 2 is more restrictive in that it contains no trait factors (i.e., only two method factors). Model 3 is also more restrictive in that it contains two freely correlated method factors and two perfectly correlated trait factors (i.e., a single climate factor). Model 4 contains two uncorrelated method factors and two freely correlated climate trait factors. Model 5 is the compliment of Model 3 in that it contains two perfectly correlated method factors and two freely correlated trait factors (i.e., a single method factor). Table 8 displays the fit statistics for each CFA model.

\section{FIGURE 1 \\ CFA MODEL 1: TWO FREELY CORRELATED METHOD FACTORS AND TWO FREELY CORRELATED CLIMATE TRAIT FACTORS}

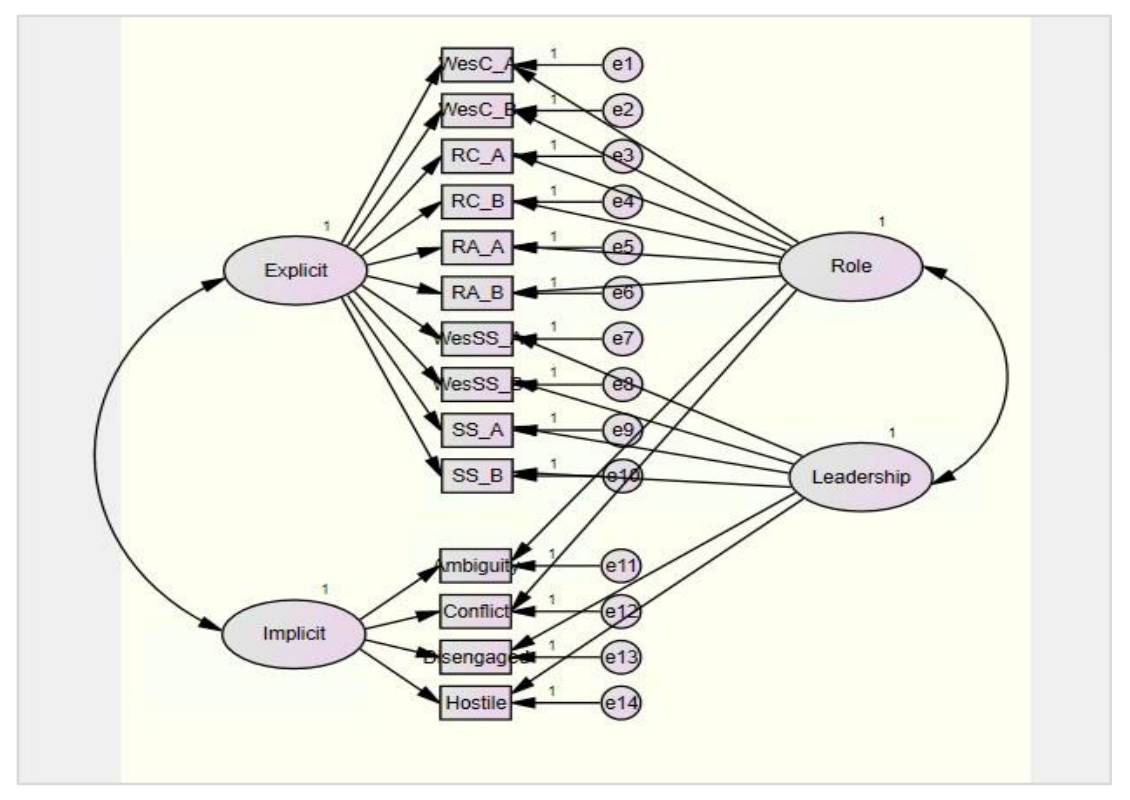




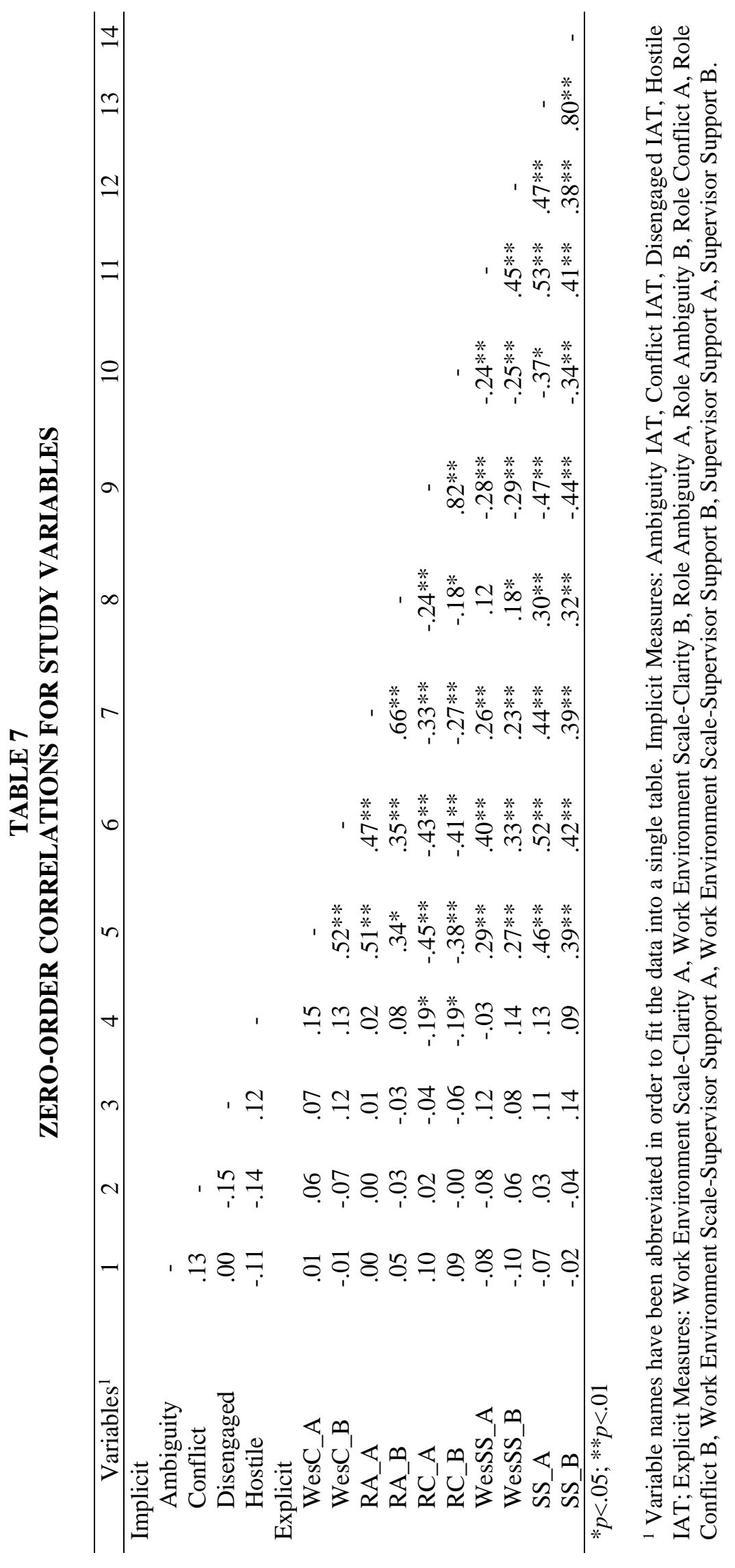




\section{TABLE 8}

SUMMARY OF GOODNESS-OF-FIT STATISTICS FOR CFA MODELS

\begin{tabular}{|c|c|c|c|c|c|}
\hline Model & $X^{2}$ & $\mathrm{df}$ & CFI & RMSEA & $90 \%$ C.I \\
\hline $\begin{array}{l}\text { 1. Two Freely Correlated Methods Factors; } \\
\text { Two Freely Correlated Climate Trait Factors }\end{array}$ & 76.30 & 61 & .98 & .041 & $.006, .067$ \\
\hline $\begin{array}{l}\text { 2. Two Freely Correlated Method Factors; No } \\
\text { Climate Trait Factors }\end{array}$ & 305.89 & 76 & .68 & .141 & $.125, .158$ \\
\hline $\begin{array}{l}\text { 3. Two Freely Correlated Method Factors; } \\
\text { Perfectly Correlated Climate Trait Factors }\end{array}$ & 153.93 & 62 & .87 & .099 & $.079, .118$ \\
\hline $\begin{array}{l}\text { 4. Two Uncorrelated Method Factors; Two } \\
\text { Freely Correlated Climate Trait Factors }\end{array}$ & 77.78 & 62 & .98 & .041 & $.000, .067$ \\
\hline $\begin{array}{l}\text { 5. Perfectly Correlated Method Factors; Two } \\
\text { Freely Correlated Climate Trait Factors }\end{array}$ & 83.12 & 62 & .97 & .047 & $.012, .072$ \\
\hline
\end{tabular}

The comparison between Model 1 and Model 2 (only method factors, no trait factors) provides evidence of convergent validity to the extent that the fit statistics for Model 2 deteriorate. The comparison between Model 1 and Model 3 provides evidence of discriminant validity to the extent the fit statistics for Model 3 (a single climate factor) deteriorate. The comparison of Model 1 and Model 4 assesses the extent to which there is common method variance across the implicit and explicit measures. The comparison of Model 1 and Model 5 provides further evidence for independent measurement methods, with two latent trait factors.

The statistics show that Model 1 fit the data well according to the recommendations provided by Bentler (1990), Byrne (2010) and others. The CFI is well above .90 and the RMSEA is below .06. When comparing the fit statistics for the more restrictive models, there is substantial degradation for Model 1 versus Model 2 and Model 1 versus Model 3, which provides support for the convergent and discriminant validity of the measures. The comparison between Model 1 and Model 4 reveals almost no difference, which suggests there is no common method variance between the implicit and explicit measures. However, the comparison between Model 1 and Model 5 also revealed little difference in the fit statistics, which begs the question: do these data support a four-factor model (Model 4) or a three-factor model (Model 5)? Table 9 displays the differential fit statistics for model comparisons.

TABLE 9

\section{DIFFERENTIAL GOODNESS-OF-FIT STATISTICS FOR MODEL COMPARISONS}

\begin{tabular}{cccc}
\hline Model Comparisons & $\Delta X^{2}$ & df & $\Delta$ CFI \\
\hline Test of Convergent Validity & & & .30 \\
Model 1 vs. Model 2 & $229.59^{* *}$ & 15 & \\
Tests of Discriminant Validity & & & .11 \\
Model 1 vs. Model 3 & $77.63^{* *}$ & 1 & .01 \\
Model 1 vs. Model 4 & 1.48 & 1 & .01 \\
Model 1 vs. Model 5 & $6.82^{* *}$ & 1 & \\
\hline
\end{tabular}

Table 10 displays the factor loadings for the hypothesized model - two organizational climate factors (leadership support and role stress) and two method factors (explicit and implicit). These loadings represent scant support for the construct validity of the implicit measures. More specifically, about half of the indicator variables for each factor had significant loadings (16 out of 28 were significant) and most of these involved explicit measures. 
TABLE 10

TRAIT AND METHOD LOADINGS FOR CFA MODEL 1

\begin{tabular}{lcccc}
\hline & Implicit & Explicit & Role & Supervisor \\
\hline Implicit Measures & & & & \\
Ambiguity & -.23 & & .07 & \\
Conflict & $-.29^{*}$ & & -.00 & .10 \\
Disengaged & .24 & & & .02 \\
Hostile & $.52^{*}$ & & & \\
Explicit Measures & & $.52^{*}$ & .38 & \\
WesC_A & & $.52^{*}$ & .36 & \\
WesC_B & $.43^{*}$ & $.77^{*}$ & \\
RA_A & .31 & $.64^{*}$ & .10 \\
RA_B & $-.94^{*}$ & .14 & $.44^{*}$ \\
RC_A & $-.86^{*}$ & & $.87^{*}$ \\
RC_B & $.32^{*}$ & $.33^{*}$ & $.67^{*}$ \\
WesSS_A & .53 & & \\
WesSS_B & $.48^{*}$ & & \\
SS_A & & & & \\
SS_B & & & & \\
\hline *p $<.05$ & & & &
\end{tabular}

\section{DISCUSSION}

This study sought to develop and validate IAT measures for two aspects of organizational climate. The intent was to develop measures that address the problem of contamination due to impression management that can plague explicit (self-report) measures. The fit statistics for the hypothesized model (two climate trait factors and two method factors) showed that the model fit the data well and comparisons with more restrictive models provided evidence of convergent and discriminant validity.

However, there was a lack of additional support for the construct validity of the implicit measures in the pattern of factor loadings for the hypothesized model and this warrants discussion. The reliability coefficients for the IATs suggest that measurement error is a problem with the implicit measures. The reliabilities for the four IATs do not meet the accepted minimum standard (.7) recommended by Nunnally (1978). Clearly, the unreliability of the implicit measures attenuated correlations with all of the measures in the MTMM matrix and this potentially explains why the pattern of factor loadings did not support the construct validity of the measures. Future research should focus on improving the psychometric properties of the four IATs that target the organizational climate factors.

The problem of latent trait models over-fitting data should also be considered. Byrne (2010), Bentler (1990), and MacCallum et al. (1996) suggest that one should be cautious when fit statistics exceed the threshold of "good fit" (CFI>.95; RMSEA<.04). Both Model 1 and Model 4 are near this threshold, which suggests they may be overfitted models. Consequently, we examined a model (Model 5) that consisted of two perfectly correlated method factors (i.e., a single method factor) and two freely correlated trait factors. Surprisingly, Model 4 and Model 5 explain the relationships among study variables equally well. However, there are compelling theoretical reasons for rejecting Model 5. The cognitive processes that implicit methods are based upon differ from those that the explicit methods involve. Kahneman (2011) describes these differences as "thinking fast" (system 1) and "thinking slow" (system 2). The effortful, deliberative system 2 processes that explicit self-report measures involve are distinct from the automatic system 1 processes that operate outside our conscious awareness. An additional model was constructed to explore whether the overfitting fell more on the method or trait side of the hypothesized model - a variant of Model 3 that contains two uncorrelated method factors and two perfectly correlated trait factors. This model (Model 6) resulted in poorer fit statistics than both Model 1 and Model 4. This finding provides further 
support for the discriminant validity of the climate traits (e.g., leadership support and role stress), but it does little to resolve the conundrum involving the method factors.

An obvious limitation of the present study is that the sample involved college students, which are not representative of the population of interest in employment settings. Although the sample had three and a half years of work experience on average, the distribution was skewed with regard to age and race/ethnicity. Furthermore, study participants were assessed under conditions that do not reflect those in employment settings. Future research might explore the extent to which the current findings generalize to other settings.

\section{ENDNOTES}

1. The authors acknowledge the contributions of research team members Viktoriia Hryshchenko, Lauren Kreig, Max Lischwe, Xin Wei Ong, Benjamin Osvath, Kurtis Payne, Tiffany Rich, Thomas Ryan, Brooke Watson, and Alana Wilcox, in making this research possible and we express our gratitude for their help.

2. All of the results reported in this paper were based upon analyses using IBM SPSS (v22) and AMOS (v18) software.

\section{REFERENCES}

Bentler, P.M. (1990). Comparative fit indexes in structural models. Psychological Bulletin, 107(2), 238246. doi: 10.1037/0033-2909.107.2.238

Boyd, B. (2018). Personalizing an implicit measure of job satisfaction (Publication No. 1987) [Doctoral dissertation, City University of New York]. CUNY Academic Works. Retrieved from https://academicworks.cuny.edu/gc_etds/1987

Byrne, B.M. (2010). Structural Equation Modeling with AMOS (Second Edition). Routledge.

Campbell, D.T., \& Fiske, D.W. (1959). Convergent and discriminant validation by the multitraitmultimethod matrix. Psychological Bulletin, 56(2), 81-105. doi: 10.1037/h0046016

Chen, X.P., Liu, D., \& Portnoy, R. (2012). A multilevel investigation of motivational cultural intelligence, organizational diversity climate, and cultural sales: Evidence from US real estate firms. Journal of Applied Psychology, 97(1), 93. doi: 10.1037/a0024697

Fazio, R., \& Olsen, M. (2003). Implicit measures in social cognition research. Annual Review of Psychology, 54(1), 297-327. doi: 10.1146/annurev.psych.54.101601.145225

Fischer, D., \& Bates, J.A. (2008). The development of an IAT for workplace integrity. In $23^{\text {rd }}$ annual meeting of the Society for Industrial and Organizational Psychology. San Francisco, CA.

Furnham, A., \& Goodstein. (1997). Organizational Climate Questionnaire (OCQ). The 1997 Review/Consulting. Pfeiffer.

Gaviria-Rivera, J.I., \& López-Zapata, E. (2019). Transformational leadership, organizational climate and job satisfaction in work teams. European Research Studies Journal, 22(3), 68-82. doi:10.11214/thalassinos.22.03.005

Greenwald, A.G., \& Farnham, S.D. (2000). Using the implicit association test to measure self-esteem and self-concept. Journal of Personality and Social Psychology, 79(6), 1022-1038. doi:10.1037/0022-3514.79.6.1022

Greenwald, A.G., Banaji, M.R., Rudman, L.A., Farnham, S.D., Nosek, B.A., \& Mellott, D.S. (2002). A unified theory of implicit attitudes, stereotypes, self-esteem, and self-concept. Psychological Review, 109(1), 3-25. doi: 10.1037/0033-295X.109.1.3

Greenwald, A.G., McGhee, D.E., \& Schwartz, J.L. (1998). Measuring individual differences in implicit cognition: The implicit association test. Journal of Personality and Social Psychology, 74(6), 1464-1480. doi: 10.1037/0022-3514.74.6.1464

Greenwald, A.G., Nosek, B.A., \& Banaji, M.R. (2003). Understanding and using the implicit association test: I. An improved scoring algorithm. Journal of Personality and Social Psychology, 85(2), 197-216. doi: 10.1037/0022- 3514.85.2.197 
Hellriegel, D., \& Slocum, J.W., Jr, (1974). Organizational climate: Measures, research and contingencies. Academy of Management Journal, 17(2), 255-280. doi: 10.5465/amr.1985.4279045

Hsu, M.L., \& Chen, F.H. (2017). The cross-level mediating effect of psychological capital on the organizational innovation climate-employee innovative behavior relationship. The Journal of Creative Behavior, 51(2), 128-139. https://doi.org/10.1002/jocb.90

Insel, P., \& Moos, R. (1972). The work environment scale. Palo Alto: Social Ecology Laboratory, Department of Psychiatry, Stanford University.

James, L.A., \& James, L.R. (1989). Integrating work environment perceptions: Explorations into the measurement of meaning. Journal of Applied Psychology, 74(5), 739-751. doi: 10.1037/00219010.74.5.739

Jones, A.P., \& James, L.R. (1977). Psychological climate: Dimensions and relationships of individual and aggregated work environment perceptions. Organizational Behavior and Human Performance, 23(2), 201-250. doi: 10.1016/0030-5073(79)90056-4

Kahneman, D. (2011). Thinking, fast and slow. Macmillan.

Karpinski, A., \& Steinman, R.B. (2006). The single category implicit association test as a measure of implicit social cognition. Journal of Personality and Social Psychology, 91(1), 16-32. doi:10.1037/0022-3514.91.1.16

Kelloway, E.K., Sivanathan, N., Francis, L., \& Barling, J. (2005). Poor leadership. Handbook of Work Stress, pp. 89-112. doi: 10.4135/9781412975995.n5

Kim, E.J., \& Park, S. (2020). Transformational leadership, knowledge sharing, organizational climate and learning: An empirical study. Leadership \& Organization Development Journal. https://doi.org/10.1108/LODJ-12-2018-0455

Ko, J., Frey, J.J., Osteen, P., \& Ahn, H. (2015). Index of Supervisor Support. PsycTESTS Dataset. doi:10.1037/t50236-000

Lane, K.A., Banaji, M.R., Nosek, B.A., \& Greenwald, A.G. (2007). Understanding and using the Implicit Association Test: IV. What we know (so far). In B. Wittenbrink \& N.S. Schwarz (Eds.), Implicit measures of attitudes: Procedures and Controversies (pp. 59-2). Guilford Press.

Leary, M.R., \& Kowalski, R.M. (1990). Impression management: A literature review and two-component model. Psychological Bulletin, 107(1), 34-47. doi: 10.1037/0033-2909.107.1.34

Litwin, G.H., \& Stringer, R.A. (1968). Motivation and organizational climate. Wiley: NY. doi:10.1037/t01302-000

MacCallum, R.C., Browne, M.W., \& Sugawara, H.M. (1996). Power analysis and determination of sample size for covariance structure modeling. Psychological Methods, 1(2), 130-149. doi:10.1037/1082-989x.1.2.130

Mawritz, M.B., Mayer, D.M., Hoobler, J.M., Wayne, S.J., \& Marinova, S.V. (2012). A trickle-down model of abusive supervision. Personnel Psychology, 65(2), 325-357. https://doi.org/10.1111/j.1744-6570.2012.01246.x

Neal, A., Griffin, M.A., \& Hart, P.M. (2000). The impact of organizational climate on safety climate and individual behavior. Safety Science, 34(1-3), 99-109. https://doi.org/10.1016/S09257535(00)00008-4

Nunnally, J. (1978). Psychometric theory. New York: McGraw-Hill.

Oberdiear, L., Fischer, D., Fiscus, T., Willis, D., Stassen, M., \& Miles, A. (2016). Development and Validation of Implicit Measures of Emotional Intelligence. Paper presented at the 28th annual meeting of the Association for Psychological Science, Chicago, IL.

Organ, D.W. (1988). Organizational citizenship behavior: The Good Soldier syndrome. Lexington, MA: Lexington.

Ostroff, C., Kinicki, A.J., \& Muhammad, R.S. (2012). Organizational culture and climate. Handbook of Psychology, 12(2), 643-676. doi: 1002/9781118133880.hop212024

Puni, A., Agyemang, C.B., \& Asamoah, E.S. (2016). Leadership styles, employee turnover intentions and counterproductive work behaviours. International Journal of Innovative Research and Development, 5(1), 1-7. 
Rizzo, J.R., House, R.J., \& Lirtzman, S.I. (1970). Role conflict and ambiguity in complex organizations. Administrative Science Quarterly, pp. 150-163. https://doi.org/10.2307/2391486

Schneider, B. (1974). Organizational type, organizational success \& the prediction of individual performance. Dept of Psychology Technical Report \#6, U of MD: Silver Springs, MD.

Schneider, B., González-Romá, V., Ostroff, C., \& West, M.A. (2017). Organizational climate and culture: Reflections on the history of the constructs in the Journal of Applied Psychology. Journal of Applied Psychology, 102(3), 468-482.

Schuler, R.S., Aldag, R.J., \& Brief, A.P. (1977). Role conflict and ambiguity: A scale analysis. Organizational Behavior and Human Performance, 20(1), 111-128. https://doi.org/10.1016/0030-5073(77)90047-2

Shanker, M. (2014). A study on organizational climate in relation to employees' intention to stay. Journal of Psychosocial Research, 9(2), 389-397.

Shanker, M. (2015). Organizational climate an antecedent to organizational commitment: An Empirical Study. Aweshkar Research Journal, 19(1), 81-94.

Skogstad, A., Einarsen, S., Torsheim, T., Aasland, M.S., \& Hetland, H. (2007). The destructiveness of laissez-faire leadership behavior. Journal of Occupational Health Psychology, 12(1), 80-92. doi:10.1037/1076-8998.12.1.80

Steffens, M.C., \& König, S. (2006). Predicting spontaneous big five behavior with implicit association tests. European Journal of Psychological Assessment, 22(1), 13-20.

Svyantek, D., \& Bott, J. (2004). Organizational culture and organizational climate measures: An integrative review. In J.C. Thomas (Ed.), Comprehensive handbook of psychological assessment, Vol. 4: Industrial and organizational assessment (pp. 507-524). Wiley.

Thakre, N., \& Shroff, N. (2016). Organizational climate, organizational role stress and job satisfaction among employees. Journal of Psychosocial Research, 11(2), 469-478.

Thumin, F., \& Thumin, L. (2011). The measurement and interpretation of organizational climate. Journal of Psychology, 145(2), 93-109. doi: 10.1080/00223980.2010.538754

Vong, L.T.N., Ngan, H.F.B., \& Lo, P.C.P. (2018). Does organizational climate moderate the relationship between job stress and intent to stay? Journal of Chinese Human Resource Management, 9(1), 220. https://doi.org/10.1108/JCHRM-09-2017-0022

Widaman, K.F. (1985). Hierarchically nested covariance structure models for multitrait-multimethod data. Applied Psychological Measurement, 9(1), 1-26.

Yıldız, M.L., \& Özcan, E.D. (2014). Organizational climate as a moderator of the relationship between transformational leadership and creativity. International Journal of Business and Management, 2(1), 76-87. 